\title{
Comparison of a Detailed and a Reduced Ethanol Oxidation Mechanism in HCCI Combustion Using a Multi-Zone Model
}

\author{
N.P. Komninos and C.D. Rakopoulos*
}

Internal Combustion Engines Laboratory, Thermal Engineering Department, School of Mechanical Engineering, National Technical University of Athens, 9 Heroon Polytechniou St., Zografou Campus, 15780 Athens, Greece

\begin{abstract}
The subject of the present study is the comparison of a detailed and a reduced ethanol oxidation mechanism. The main scope is to determine whether the reduction of species and reactions, which reduces the simulation time, affects the prediction of performance and emissions from a multi-zone model. The numerical study is conducted using a previously published multi-zone model, which incorporates chemical kinetics for the estimation of reaction rates. The model also includes sub-models for the description of heat transfer, mass transfer and crevice flow, and produces a temperature distribution within the combustion chamber. The cases simulated and examined involve ethanol HCCI combustion in a reciprocating internal combustion engine with various equivalence ratios. At each load two simulations are conducted with the multi-zone model, i.e. one with each oxidation mechanism, and the results are compared to the corresponding experimental results. The comparison of the two oxidation mechanisms includes simulation times, pressure traces, heat release rates, composition and quantity of unburned hydrocarbons emissions, including their composition, carbon monoxide and nitrogen oxides emissions. The reduced model decreases the simulation time by $50 \%$. The two mechanisms produce almost identical results as regards ignition timing. The pollutant emissions predicted are essentially the same for the two mechanisms, with the greatest difference occurring between predicted $\mathrm{CO}$ emissions ( 9\%) at the low load cases.
\end{abstract}

Keywords: $\mathrm{HCCI}$ engine, Multi-zone model, Ethanol, Oxidation mechanism, $\mathrm{HC}$ emissions, $\mathrm{CO}$ emissions, $\mathrm{NO}_{\mathrm{x}}$ emissions.

\section{INTRODUCTION}

Bio-fuels have received a growing attention in the past years as potential fuels for internal combustion engines [1-6]. The benefits from the gradual replacement of fossil fuels by bio-fuels are both socioeconomic and environmental. The production of bio-fuels decreases the energy dependence from fossil fuels and supports the agricultural population [3,7]. Moreover, bio-fuels have the potential to reduce certain pollutant emissions such as greenhouse gases due to their renewable character, and particulates due to their oxygenated chemical structure [3]. For these reasons, biofuels have been used in compression ignition (CI) $[3-5,8,9]$ and spark ignition (SI) engines [10-12] as neat fuels or supplements.

In parallel to the research related to bio-fuels, a relatively new combustion concept has been developed especially in the last 10 years, i.e. the homogeneous charge compression ignition (HCCI) combustion. HCCI combustion shares common features with the SI engine due to the premixed nature of the charge [13]. It is also similar to CI engines since ignition relies upon auto ignition of the compressed charge. The benefits of using HCCI combustion are the

*Address correspondence to this author at the Internal Combustion Engines Laboratory, Thermal Engineering Department, School of Mechanical Engineering, National Technical University of Athens, 9 Heroon Polytechniou St., Zografou Campus, 15780 Athens, Greece; Tel.: +30 210 7723529; Fax: +30 210 7723531; E-mail: cdrakops@central.ntua.gr absence of soot emissions, low $\mathrm{NO}_{\mathrm{x}}$ emissions and increased thermal efficiency provided that ignition timing is favorable [13]. However, unburned hydrocarbons (HC) and $\mathrm{CO}$ emissions remain at a high level. Moreover, in the absence of direct means to control ignition, the ignition timing and combustion duration strongly depend on chemical kinetics, which are connected to the type of fuel used. These issues are the most challenging problems related to HCCI combustion.

Among the various techniques used for controlling ignition and combustion is the use of neat fuels and blends thereof [14-17]. The main aim of these experimental studies is to investigate the reactivity of the fuels relative to HCCI performance and emissions. Among the fuels - and blends thereof - being tested are PRF fuels, methane, reformed gas and hydrogen, and bio-fuels such as methanol, ethanol, biodiesel, diethyl ether etc. Ethanol has been used as a fuel in HCCI engines, either as neat ethanol $[18,19]$ or as a supplement $[20,21]$. Current research also focuses on using wet ethanol in HCCI combustion since its production is cheaper and energy-saving [22].

Towards understanding the reactivity of conventional fuels and bio-fuels, simulation models have been used, including in the vast majority single zone models and to a much lesser extent computational fluid dynamics (CFD) and simplified multi-zone models [20,23-28]. These models simulate the compression, combustion and expansion processes in HCCI engines, and are being used for understanding the 
chemical processes involved. They are also used to evaluate various chemical mechanisms, some of which include numerous species and reactions [25]. The size of the chemical mechanism used determines the total simulation time required and imposes a limit on the use of such mechanisms in the more descriptive multi-dimensional or multi-zone models. This motivates researchers to reduce detailed chemical mechanisms, by ignoring appropriate species and reactions, and to use mostly single zone models for the study of the detailed and reduced chemical mechanisms.

Single zone models can be used to investigate the ignition timing and species evolution within the combustion chamber, which is considered uniform by definition [24,29]. They can also be used to clarify the effect of various parameters such as exhaust gas recirculation (EGR), inlet temperature, engine speed, compression ratio etc, mainly at the onset of combustion. Although ignition timing and species reactivity are indeed phenomena of interest, the performance of a detailed or reduced chemical mechanism under non-uniform in-cylinder conditions is equally significant. Such nonuniform conditions are encountered in real engines and can be described only with the use of multi-zone and CFD models. Complex processes such as heat and mass transfer determine the temperature field within the combustion chamber and affect significantly the formation of $\mathrm{CO}$ and $\mathrm{HC}$ [30]. Since the formation of these pollutants also depends on chemical kinetics, their prediction imposes a challenge to any chemical mechanism, especially the reduced ones. The challenge lies in the adequate performance of the chemical mechanism in low temperature regions, which exchange mass with the hotter regions of the combustion chamber in a perpetual manner. It is in these regions that $\mathrm{CO}$ and $\mathrm{HC}$ are formed as a result of the complex interactions previously described. Thus, if performance and especially $\mathrm{CO}$ and $\mathrm{HC}$ emissions are to be predicted at least qualitatively, a reduced chemical mechanism must be adequate to describe oxidation processes under such diverse conditions.

This is the focus of the present study, namely to evaluate the relative performance of two ethanol oxidation mechanisms, one detailed and one reduced -the latter derived from the former- by incorporating them into a multi-zone model. The multi-zone model consists of zones, which are given spatial locations and dimensions. The zones exchange heat, based on their temperature difference, and mass according to their configuration to maintain the in-cylinder pressure uniform. The model includes a zone representing the crevice regions, which is considered to be a source of $\mathrm{HC}$. The variation of mixture composition due to combustion is determined using chemical kinetics and the corresponding chemical mechanism. With the description of these interacting and thermodynamically diverse regions, the chemical mechanisms are compared on a more realistic basis. The features compared are the simulation time, predicted pressure traces, heat release rates, $\mathrm{NO}_{\mathrm{x}}$ and $\mathrm{CO}$ emissions and $\mathrm{HC}$ composition and quantity. The results obtained from the simulation using the two mechanisms are also compared to the corresponding experimental results to provide a realistic framework for the study. The comparison to experimental results triggered some considerations regarding $\mathrm{HC}$ emissions from oxygenated fuels, which are qualitatively discussed in this study and will form the subject of future research.

\section{MODEL DESCRIPTION}

In this section a brief outline of the multi-zone model is provided, since its development has been presented in detail in previous reports [30-32].

\subsection{Zone Configuration}

As shown in Fig. (1) the combustion chamber is divided into three different types of zones, i.e. the core zone, the outer zones and the crevice zone. The core zone is a cylinder, each of the outer zones is a cylindrical annulus and the crevice zone lies beneath the outmost zone. The crevice zone is a fraction of the clearance volume and represents the crevice regions that communicate directly with the combustion chamber, i.e. the region above and behind the first compression ring, the head gasket crevice etc.

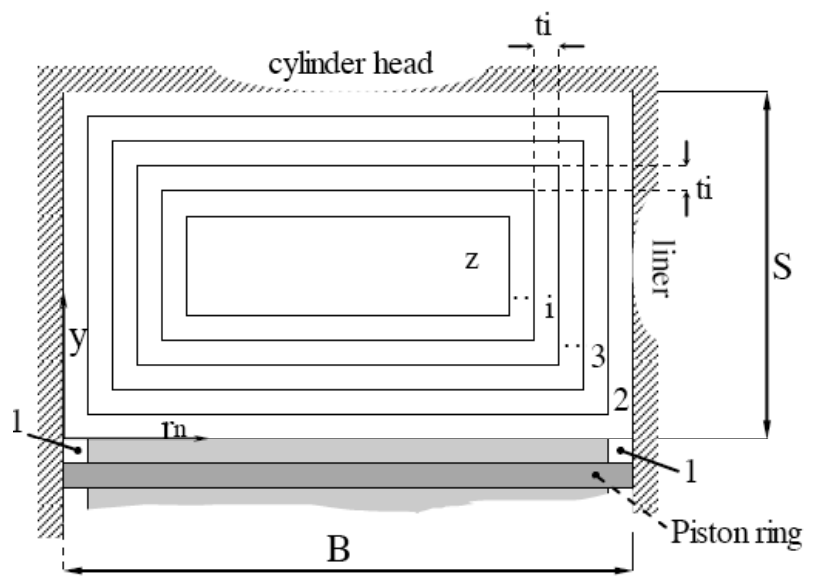

Fig. (1). Schematic of the multi-zone model zones configuration.

The volume of the remaining zones varies throughout the engine cycle and it is calculated according to their thickness. As seen in Fig. (1), the thickness of each zone is the distance between its inner and its outer boundary. Since the core zone has only an outer boundary, its thickness is defined as half its height. As the piston head moves during compression and expansion, the distance of the bottom boundary of each zone from the piston head is held constant. Therefore, the thickness of all outer zones, which is considered the same in the $\mathrm{x}-$ and $\mathrm{y}$ - direction, is constant during the cycle. On the contrary, the thickness of the core zone is altered since its height decreases during compression and increases during expansion. At top dead center (TDC) position, the sum of all zone thicknesses must equal half the cylinder clearance height:

$$
\left.\sum_{i=2}^{z} t_{i}\right|_{T D C}=\frac{S_{\min }}{2}
$$

\subsection{The First Law of Thermodynamics Applied to the Multi-Zone Model}

The combustion chamber as a whole is considered as a closed system during compression combustion and expansion, i.e. charge blow-by is not considered. On the contrary, each zone of the multi-zone model is considered as an open thermodynamic system. All zones exchange heat, mass, species and enthalpy based on the configuration shown in Fig. (1). This implies that any of the aforementioned interactions 
(heat and mass transfer) occurs through the interface of neighboring zones. At the combustion chamber boundaries heat is transferred to the combustion chamber wall only through the crevice zone (zone 1), which is considered to assume the wall temperature, and the outmost zone (zone 2), which is considered to be in contact with the wall. During the engine cycle, the volume of each zone changes due to the piston motion, and can be directly calculated based on the zone thickness and the configuration shown in Fig. (1). This volume change of each zone induces mass transfer between neighboring zones to maintain uniform pressure within the combustion chamber. Moreover, mass exchange can also be the result of combustion in a zone or its neighboring ones. Since blow-by is neglected, the conservation of mass principle requires that at any instant the total mass within the combustion chamber remains unaltered. Treating each zone as an open thermodynamic system, the First Law of Thermodynamics takes the following form:

$d U_{i}=Q_{i}-P_{c y l} d V_{i}+\sum_{j=1}^{J} n_{j}^{\text {flow,in }} h_{j}-\sum_{j=1}^{J} n_{j}^{\text {flow, out }} h_{j}$, ... (2)

$i=1, z$

where $d U_{i}$ is the change in the internal energy of the gas in zone $i, n_{j}$ are the kmoles of species $j$ transferred in or out of zone $i$, and $h_{j}$ is the corresponding molar specific enthalpy of species $j$.

According to Eq. (2), the change in the internal energy of the gas in each zone depends upon the net heat gained $Q_{i}$ by zone $i$, the work produced or consumed $P_{c y l} d V_{i}$, and the enthalpy inflow and outflow from the neighboring zones. The enthalpy flow between zones represents the convective heat transfer term, i.e. energy transfer due to bulk motion. As soon as the mass flowing from each zone to the neighboring zones is determined, the species transfer and the enthalpy transfer term(s) in Eq. (2) are easily evaluated, assuming that the mass flowing between neighboring zones has the thermodynamic properties (i.e. temperature, specific enthalpy and chemical species composition) of the zone from which it originates. The following subsections describe the procedures applied for the estimation of the heat exchange term $Q_{i}$ and the determination of the mass flow between zones.

\subsection{Heat Transfer}

In the multi-zone model, heat is transferred from the outmost zone and the crevices to the combustion chamber wall as well as between neighboring zones as shown in Fig. (2). The crevices are considered to rapidly assume the wall temperature and preserve this for the remaining part of the closed cycle.

For the estimation of the wall heat flux $\dot{q}_{w}$, the no-slip boundary condition [33] is applied to the gas in contact with the wall. According to the no-slip condition, the fluid in contact with the combustion chamber wall assumes the velocity of the boundary (wall) and it is thus considered stationary. Consequently, heat is transferred through this thin fluid layer only via conduction. Therefore, the wall heat flux is estimated by:

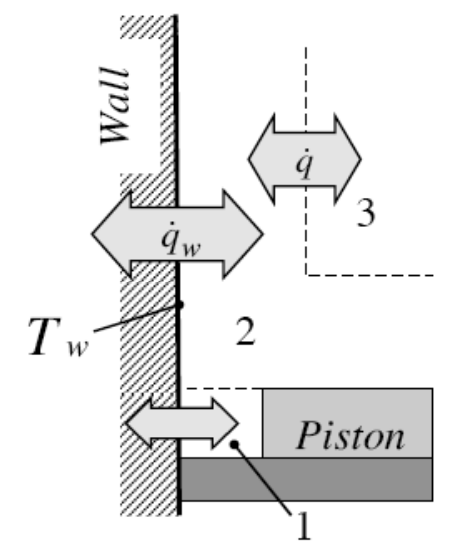

Fig. (2). Description of heat interaction between zones, and schematic of the heat transfer between zones and the combustion chamber wall.

$\dot{q}_{w}=-\left.k_{w} \frac{\partial T}{\partial r_{n}}\right|_{r_{n}=0} \quad$ (wall boundary condition)

where $k_{w}$ is the conductivity of the charge at the cylinder wall temperature, $r_{n}$ is the normal distance from the wall, and $\left.\frac{\partial T}{\partial r_{n}}\right|_{r_{n}=0}$ the temperature gradient at the wall (i.e. at $r_{n}=0$ ). The temperature gradient at the wall is approximated numerically by the relations:

$$
\begin{aligned}
& \left.\frac{\partial T}{\partial r_{n}}\right|_{r_{n}=0} \cong\left(\frac{T_{2}-T_{w}}{t_{2} / 2}\right)^{2}\left(\frac{T_{3}-T_{2}}{\left(t_{2}+t_{3}\right) / 2}\right)^{-1} \text {, when } \\
& T_{w}<T_{2}<T_{3} \text { and } T_{w}<\bar{T} \\
& \left.\frac{\partial T}{\partial r_{n}}\right|_{r_{n}=0} \cong \frac{T_{2}-T_{w}}{t_{2} / 2}, \text { in all other cases }
\end{aligned}
$$

The heat transfer sub-model also caters for heat transfer between zones. This is incorporated into the multi-zone model by considering heat transfer via a mechanism similar to conduction, i.e. the heat flux between neighboring zones is based on their temperature difference and mean distance, so that:

$$
\dot{q}=-k_{t o t} \frac{\partial T}{\partial r_{n}}
$$

The amount of heat exchanged at the interface of two neighboring zones is calculated by multiplying the heat flux by the interface area and the time step used. The net heat exchanged for each zone $Q_{i}$ is then the algebraic sum of the heat exchanged with its outer and inner zone.

For the determination of the total conductivity in Eq. (5), the approach of Yang and Martin [34] is followed:

$k_{\text {tot }}=k_{l}+k_{t}$ 
The ratio of turbulent to laminar conductivity is calculated using the following formula:

$$
\frac{k_{t}}{k_{l}}=\frac{\operatorname{Pr}_{l}}{\operatorname{Pr}_{t}} \frac{\mu_{t}}{\mu_{l}}
$$

The formula presented above presupposes swirl dominated flows and it is used in the absence of other data. The viscosity ratio of Eq. (7) is calculated from the formula:

$$
\frac{\mu_{t}}{\mu_{l}}=\kappa r_{n}^{+}\left[1-\exp \left(-2 \alpha \kappa r_{n}^{+}\right)\right]
$$

where the dimensionless normal distance from the wall $r_{n}^{+}$, which is effectively a Reynolds number, is given as:

$$
r_{n}^{+}=\frac{u^{*}}{\mu_{w}} \int_{0}^{r_{n}} \rho d r_{n}
$$

where $\kappa=0.41$ is the von Karman constant, $\alpha=0.06$ and $r_{n}$ is the normal distance from the wall. The characteristic velocity $u^{*}$ is considered to be proportional to the engine speed. This proportionality constant was taken equal to 0.06 , for the purposes of the present study, and it was chosen in a way to match mainly the compression and peak combustion pressures.

The Yang and Martin approach has been used in the past by other authors [35] for the estimation of heat losses in HCCI engines via CFD modeling, and for the estimation of wall heat transfer in premixed charge engine combustion [36]. More recently, the Yang and Martin formulas for turbulent conductivity and the adaptation to HCCI multi-zone modeling, as presented herein and in previous studies by the authors [30,31], has been adopted by other researches in their HCCI multi-zone models [37-39].

\subsection{Mass Transfer}

Mass is transferred between zones to maintain the pressure uniform inside the combustion chamber. The mass transferred between zones is calculated using the ideal gas equation of state along with the conservation of mass within the combustion chamber. The assumption of uniform pressure and the use of the ideal gas equation lead to the equations:

$$
P_{c y l} V_{i}=\frac{m_{i}}{\bar{M}_{i}} R_{u} T_{i}, i=1, z
$$

Solving Eq. (10) for the mass of each zone and summing up, we end up with:

$$
\sum_{i=1}^{z} m_{i}=m_{c y l}=\sum_{i=1}^{z} \frac{P_{c y l} V_{i} \bar{M}_{i}}{R_{u} T_{i}}
$$

Equation (11) relates the cylinder pressure to the total charge mass, which remains constant since blow-by is not taken into account. Therefore, the mean cylinder pressure at each crank angle (CA) step is calculated from:

$$
P_{c y l}=\frac{m_{c y l} R_{u}}{\sum_{i=1}^{z} \frac{V_{i} \bar{M}_{i}}{T_{i}}}
$$

Once the uniform pressure is calculated, the mass of each zone is determined using the equation of state for an ideal gas:

$m_{i}=P_{c y l} \frac{V_{i} \bar{M}_{i}}{R_{u} T_{i}}, i=1, z \ldots$

The mass change of each zone during the crank angle (CA) step is the difference between the zone mass calculated by Eq. (13) and the zone mass at the previous CA step:

$$
\Delta m_{i}=m_{i}-m_{i}^{\text {previous } C A}, i=1, z
$$

This mass change of each zone, which is calculated thermodynamically by Eqs. (13) and (14), equals the net mass flow from its neighboring zones. Taking into account the configuration of the zones, mass flows only between neighboring zones:

$$
\Delta m_{i}=m_{i-1 \rightarrow i}^{\text {flow }}-m_{i \rightarrow i+1}^{\text {flow }}
$$

The mass flow between zones can be calculated by successively applying Eq. (15) for all zones starting from zone 1 (crevice) for which the mass change $\Delta m_{1}$ is equal to $m_{1 \rightarrow 2}^{\text {flow }}$, i.e. the mass flowing through the interface of zones 1 and 2. The latter holds since blow-by is not accounted for in the model.

The transfer of species is calculated based on the assumption that the mass flowing from a zone to its neighboring one has the chemical composition of the zone from which it originates. This mixing, owed to mass transfer, affects the final chemical composition of the zones and the average zone molar mass $\bar{M}_{i}$ used in Eqs. (12) and (13). Both of these effects are taken into account in the model during convergence at each CA step.

The mass transfer procedure presented herein has been adopted by other researches for the simulation of mass transfer in a relatively new combustion concept, namely the porous medium engine [40].

\subsection{Combustion and Pollutants Formation}

Combustion is described using the set of chemical reactions included in the two ethanol oxidation mechanisms. The detailed mechanism has been developed by Marinov [41]. It consists of 57 species and 383 reactions, and is available online [42]. The detailed mechanism of Marinov has been recently reduced by Röhl and Peters at the Institute of Combustion Technology of Aachen University, Germany [43]. Their reduced mechanism includes 38 species and 228 reactions, and it is also available online [44]. The 19 species excluded in the Röhl and Peters' mechanism are $\mathrm{HCOH}$, formic acid $(\mathrm{HCOOH})$, methanol $\left(\mathrm{CH}_{3} \mathrm{OH}\right), \mathrm{C}_{2} \mathrm{O}, \mathrm{CHOCHO}$, $\mathrm{HOC}_{2} \mathrm{H}_{4} \mathrm{O}_{2}, \quad \mathrm{CH}_{2} \mathrm{CHCO}, \quad \mathrm{CH}_{2} \mathrm{CHCHO}, \quad \mathrm{CH}_{3} \mathrm{CHCO}$, 


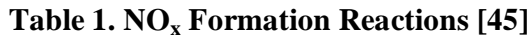

\begin{tabular}{|l|l|}
\hline 1. & $\mathrm{~N}+\mathrm{NO}=\mathrm{N}_{2}+\mathrm{O}$ \\
\hline 2. & $\mathrm{~N}+\mathrm{O}_{2}=\mathrm{NO}+\mathrm{O}$ \\
\hline 3. & $\mathrm{~N}+\mathrm{OH}=\mathrm{NO}+\mathrm{H}$ \\
\hline 4. & $\mathrm{NO}+\mathrm{HO}_{2}=\mathrm{NO}_{2}+\mathrm{OH}$ \\
\hline 5. & $\mathrm{NO}_{2}+\mathrm{O}=\mathrm{NO}+\mathrm{O}_{2}$ \\
\hline 6. & $\mathrm{NO}_{2}+\mathrm{H}=\mathrm{NO}+\mathrm{OH}$ \\
\hline 7. & $\mathrm{NO}_{+} \mathrm{O}+\mathrm{M}=\mathrm{NO}_{2}+\mathrm{M}$ \\
\hline 8. & $\mathrm{~N}+\mathrm{CO}=\mathrm{NO}+\mathrm{CO}$ \\
\hline 9. & $\mathrm{~N}_{2} \mathrm{O}+\mathrm{O}=\mathrm{NO}+\mathrm{NO}$ \\
\hline 10. & $\mathrm{~N}_{2} \mathrm{O}+\mathrm{O}=\mathrm{N}_{2}+\mathrm{O}_{2}$ \\
\hline 11. & $\mathrm{~N}_{2} \mathrm{O}+\mathrm{H}=\mathrm{N}_{2}+\mathrm{OH}$ \\
\hline 12. & $\mathrm{~N}_{2} \mathrm{O}+\mathrm{M}=\mathrm{N}_{2}+\mathrm{O}+\mathrm{M}$ \\
\hline 13. & $\mathrm{~N}_{2} \mathrm{O}+\mathrm{OH}=\mathrm{N}_{2}+\mathrm{HO}$ \\
\hline
\end{tabular}

$\mathrm{CH}_{2} \mathrm{CHCH}_{2} \mathrm{O}, \mathrm{a}-\mathrm{C}_{3} \mathrm{H}_{4}, \mathrm{p}-\mathrm{C}_{3} \mathrm{H}_{4}, \mathrm{a}-\mathrm{C}_{3} \mathrm{H}_{5}, \mathrm{p}-\mathrm{C}_{3} \mathrm{H}_{5}, \mathrm{~s}-\mathrm{C}_{3} \mathrm{H}_{5}$, $\mathrm{C}_{3} \mathrm{H}_{6}, \mathrm{i}-\mathrm{C}_{3} \mathrm{H}_{7}, \mathrm{n}-\mathrm{C}_{3} \mathrm{H}_{7}$ and $\mathrm{C}_{3} \mathrm{H}_{8}$. As will be shown subsequently, most of these species are found in very small amounts at the highest and lowest load cases studied herein.

Since the aforementioned mechanisms do not provide for $\mathrm{NO}_{\mathrm{x}}$ reactions, they have been augmented by $\mathrm{NO}_{\mathrm{x}}$ formation reactions including species such as $\mathrm{NO}_{2}, \mathrm{NO}, \mathrm{N}_{2} \mathrm{O}$ and $\mathrm{N}$. $\mathrm{The}_{\mathrm{NO}}$ formation reactions were adopted by another oxidation model, namely the oxidation model of isooctane created by Golovitchev at the Chalmers University, Sweden [45]. The additional $\mathrm{NO}_{\mathrm{x}}$ reactions and the relevant species are presented in Table 1. The final mechanisms used along with the number of species and reactions considered are given in Table 2.

Since mass transfer is taken into account in the present multi-zone model, the final amount of each chemical species in each zone -including $\mathrm{CO}, \mathrm{HC}$ and $\mathrm{NO}_{\mathrm{x}}-$ is determined by its net formation rate and by the net amount of the species transferred to the zone via mass transfer. The exchange of species between zones and, especially, the transfer of combustion products in and out of the crevices play an important role in the formation of $\mathrm{CO}$ and $\mathrm{HC}$ emissions.

\section{RESULTS AND DISCUSSION}

\subsection{Chemical Mechanism Evaluation Procedure}

The validation of any chemical mechanism is usually conducted by comparing the predictions of each mechanism to experimental data. These data include species concentrations in flow or stirred reactors, laminar flame speeds in con- stant volume bombs, ignition delay data from shock tubes etc $[41,43,46]$. This fundamental testing of each chemical mechanism is of course necessary for the understanding of the reactions and species involved. However, the inclusion of many reactions and species increases the computational time required for the simulation of the oxidation process. Moreover, some detailed mechanisms also include species and reactions that are important under fuel rich conditions, which do not take place in HCCI engines. From the perspective of HCCI combustion modeling, it is obvious that the details necessary for the simulation of the combustion process are less demanding. Computational time, on the other hand, is a key factor, especially when these mechanisms are designed for CFD or multi-zone model simulations. However, care should be exercised when using reduced models and their applicability range should be tested.

The current study focuses on this latter issue. As stated in the Introduction, the main objective is to compare the two ethanol oxidation mechanisms presented in subsection 2.5, and determine whether the reduction of a detailed chemical mechanism induces significant alterations to the predicted performance and emissions of a HCCI engine. Apparently, such a comparison can be done without any reference to experimental data. However, in order for the simulation to produce realistic results, some of the experimental cases presented in Ref. [18] by the Lund Institute of Technology, Sweden, have been included herein for reference. The experiments conducted by these researchers refer, among others, to ethanol-fueled HCCI engine. The details of the engine and the operating conditions, which were used in the experiments and adopted in the present study, are provided in the next subsection.

It should be emphasized that the primary purpose of the study is not to validate the multi-zone model under the actual experimental conditions, but rather to provide a more realistic framework for the comparison of the two chemical mechanisms.

\subsection{Engine Specifications - Operating and Modeling Conditions}

The experimental data used for reference in the present work were provided by Lund Institute of Technology from a relevant experimental investigation. The details of this investigation have been published in Ref. [18] and involve the use of ethanol as a HCCI fuel under various equivalence ratios. The engine considered was a Volvo TD100 diesel engine, modified to operate in HCCI mode. This was achieved by preheating the air stream and injecting the fuel into the air stream prior to its entrance to the engine cylinder. The main design data of the engine used in the experiments are given in Table 3, while the corresponding operating conditions, which include five different load cases, are shown in Table 4. The term $\phi$ (phi) included in Table 4 is defined as the fuel-

Table 2. Oxidation Mechanisms used in the Simulation

\begin{tabular}{|l|l|l|}
\hline \multicolumn{1}{|c|}{ Source } & \multicolumn{1}{|c|}{ Species } & \multicolumn{1}{|c|}{ Reactions } \\
\hline \hline Marinov [41] with $\mathrm{NO}_{\mathrm{x}}$ reactions from [45] & 61 & 396 \\
\hline Röhl and Peters [43] with $\mathrm{NO}_{\mathrm{x}}$ reactions from [45] & 42 & 241 \\
\hline
\end{tabular}


Table 3. Engine Main Design Data

\begin{tabular}{|c|c|}
\hline Compression ratio & $21: 1$ \\
\hline Bore $(\mathrm{mm})$ & 120.65 \\
\hline Stroke $(\mathrm{mm})$ & 140 \\
\hline Connecting rod $(\mathrm{mm})$ & 260 \\
\hline EVO $($ deg bBDC) & 39 \\
\hline EVC $($ deg bTDC) & 10 \\
\hline IVO (deg aTDC) & 5 \\
\hline IVC (deg aBDC) & 13 \\
\hline
\end{tabular}

Table 4. Engine operating Conditions

\begin{tabular}{|l|l|}
\hline Fuel & $\mathrm{C}_{2} \mathrm{H}_{5} \mathrm{OH}$ \\
\hline Engine speed (rpm) & 994 \\
\hline Fuel-air equivalence ratio $\phi$ & $0.15-0.26$ \\
\hline Inlet conditions & Naturally aspirated \\
\hline Air inlet temperature $\mathrm{T}_{\text {in }}\left({ }^{\circ} \mathrm{C}\right)$ & 120 (preheated air) \\
\hline Residual fraction (est.) $(\%)$ & 3.5 \\
\hline
\end{tabular}

air equivalence ratio, i.e. the actual fuel-air ratio divided by its stoichiometric value.

Sixteen (16) zones were used for the multi-zone model simulation, including the crevice zone (zone 1). The crevice volume is considered constant throughout the engine cycle and estimated to be about $1.5 \mathrm{~cm}^{3}$.

The temperature and composition at IVC event are considered uniform throughout the cylinder, and the wall temperature was estimated at around $450 \mathrm{~K}$ due to the high air inlet temperature required to ignite ethanol. The procedure followed for each load case was to run a simulation with the reduced chemical mechanism of Röhl and Peters to determine $T_{\mathrm{ivc}}$, which results to ignition close to the one observed in the experiments. This was necessary since $T_{\mathrm{ivc}}$ is generally different from the air inlet temperature $T_{\text {in }}$ [31] and affects the ignition timing. Subsequently, the detailed mechanism of Marinov was used to simulate the same load case, while using the same $T_{\mathrm{ivc}}$ as estimated by the aforementioned procedure, and also keeping all other modeling parameters unaltered. This provides the basis for the direct comparison of the two mechanisms under identical HCCI operating conditions.

The results presented in the following subsections aim mainly to the comparison of the two chemical mechanisms considered. However, as stated previously, comparison to experimental results is also given for reference.

\subsection{Computational Time}

The reduction in computational time when using Röhl and Peters' oxidation mechanism instead of Marinov's, is shown in Fig. (3).

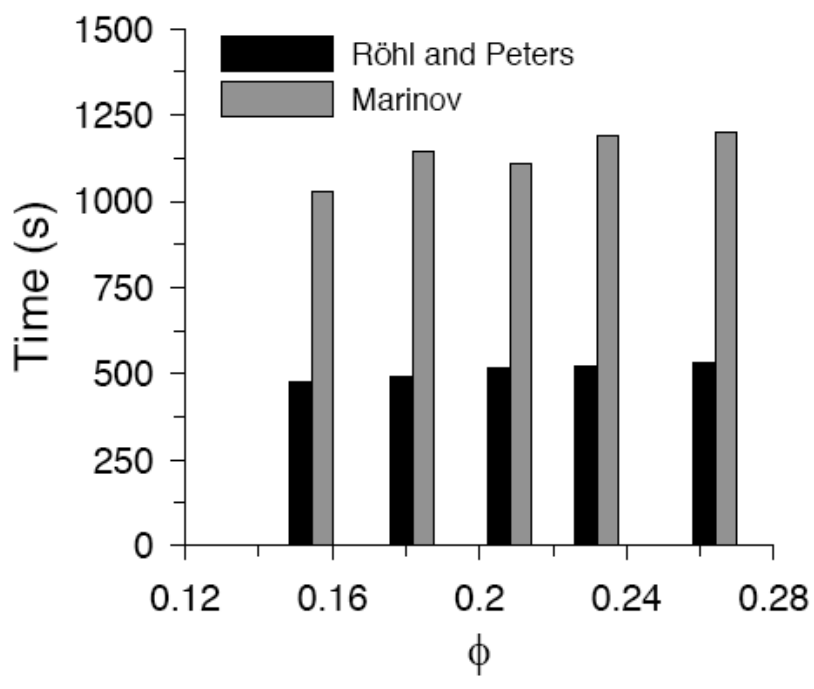

Fig. (3). Computational time required by the multi-zone simulation for the five load cases examined, using the two oxidation mechanisms.

The computational time corresponds to an Intel Core Duo $2 \mathrm{GHz}$ processor. Röhl and Peters' mechanism required approximately $50 \%$ of the computational time. Considering the fact that their mechanism includes about $2 / 3$ of the species considered in Marinov's oxidation mechanism, the nonlinear dependence of computational time on the number of species is evident. The reduction in computational time is significant and allows for the use of such reduced mechanisms in multi-zone and especially CFD modeling, in which computational time is a significant factor.

However, care should be exercised when using reduced mechanisms, since a loss of accuracy often accompanies such reductions. This is the subject of the following subsections, which examine the effect of species and reactions reduction on the basic performance and emissions characteristics of HCCI combustion.

\subsection{Pressure Traces and Heat Release Rates}

In Figs. (4a-4e), a comparison is shown between experimental and simulated pressure traces and heat release rates. Comparing the simulated pressure traces and heat release rates, it can be seen that a shift in ignition timing occurs. Röhl and Peters' mechanism predicts a slightly earlier combustion phasing than that of Marinov's for the same $T_{i v c}$, which was determined using the former mechanism. Viewed closer, this is not delayed ignition, but rather overestimation of combustion rate when using the Röhl and Peters' mechanism. This becomes apparent by considering the fact that the first appreciable non-zero heat release occurs at the same CA for the two mechanisms and the heat release rates are identical for the following 4 degrees of CA. After this period, the Röhl and Peters' mechanism slightly overestimates the combustion rate. Loosely viewed, this can be considered delayed ignition depending on the definition of ignition angle, i.e. at 5 or $10 \%$ heat released, since up to the point where the two predicted heat release rates diverge only $3 \%$ of the total fuel energy has been released. This slight underestimation of ignition delay in Röhl and Peters' mechanism was also pointed out by the researchers in Ref. [43]. 

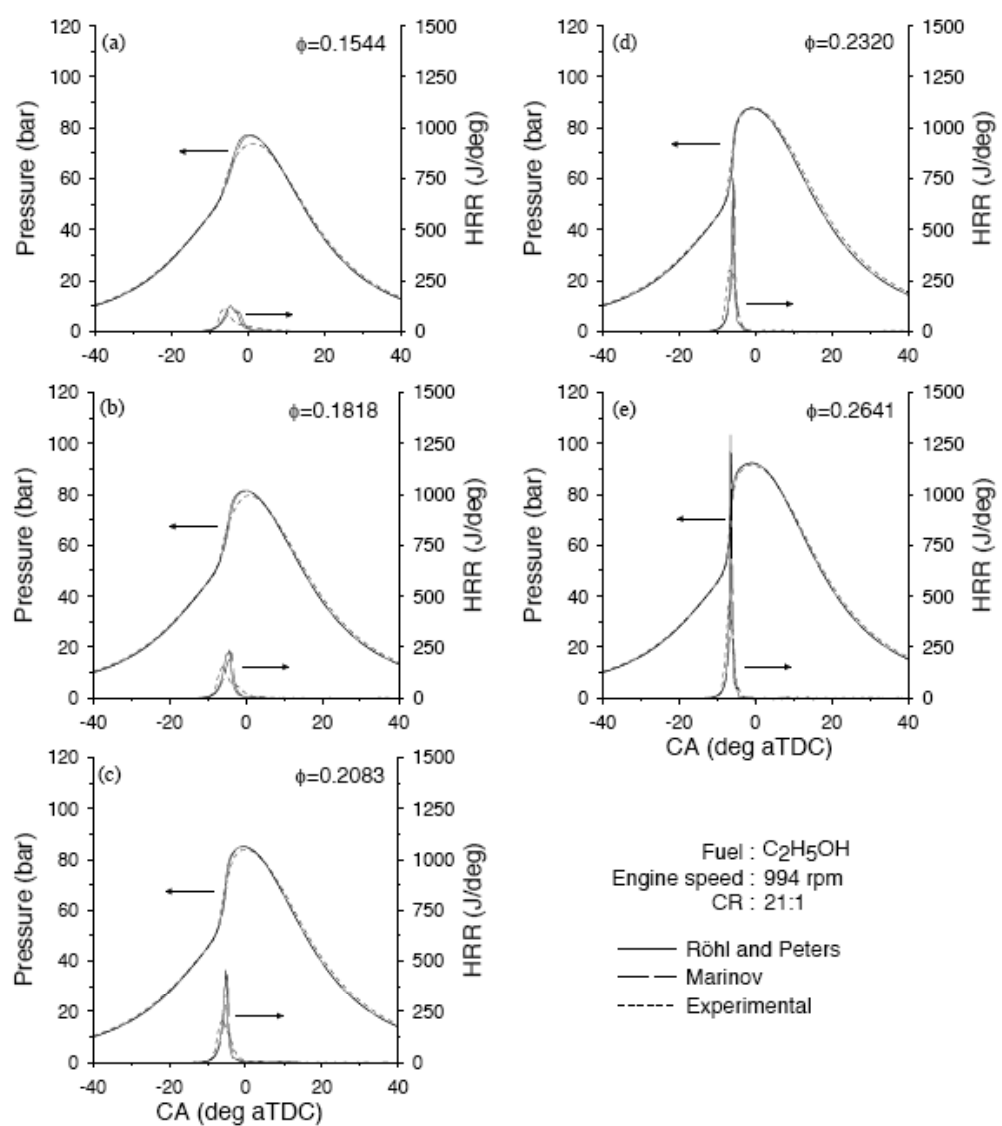

Fig. (4). Experimental and simulated pressure traces and heat release rates for the five load cases examined, for various values of $\phi$. (a) $\phi=0.1544$, (b) $\phi=0.1818$, (c) $\phi=0.2083$, (d) $\phi=0.2320$, (e) $\phi=0.2641$.

Comparing the experimental results with the simulated ones, it can be seen that at high loads the match is adequate with a slight underestimation of expansion pressures. At low loads, there is an overshooting of peak combustion pressure.

It has to be noted though that at low load conditions, combustion efficiency deteriorates, and for the lowest load cases (Figs. $\mathbf{4 a}$ and $\mathbf{4 b}$ ) it was determined experimentally to be about $90-95 \%$. Under such low load conditions (imep int $^{<}$ 2.2 bar), inhomogeneties within the combustion chamber seem to predominate. This could justify the prolonged heat release observed in the experimental HRR for the two low load cases and the overshooting of simulated pressure traces.

The overestimation of heat release rate observed in the higher load cases could be attributed partly to the unavoidable smoothing of the experimental heat release rate and also to the different models used for the estimation of heat losses during combustion.

\subsection{Emissions}

The emissions presented in this subsection refer to specific emissions expressed in $\mathrm{g} / \mathrm{kWh}$ and evaluated in the closed part of the engine cycle, i.e. from IVC to EVO. Specific emissions were also originally presented by the experimenters at the Lund Institute of Technology [18]. The emissions were presented as $\mathrm{g} / \mathrm{kWh}_{\text {net }}$ and referred to the entire four stroke cycle. The transformation to $\mathrm{g} / \mathrm{kWh}$ IVC-Evo was achieved by taking into account the work produced during the entire cycle and the work produced during the IVC-EVO interval.

\section{6. $\mathrm{NO}_{\mathrm{x}}$ Emissions}

As already mentioned, the two oxidation mechanisms did not originally include NOx formation reaction. Therefore, additional species and reactions were included as described in subsection 2.5. The nitrogen oxides $\left(\mathrm{NO}_{\mathrm{x}}=\mathrm{NO}+\mathrm{NO}_{2}\right)$ emissions results obtained from these augmented oxidation mechanisms for the five different load cases examined are shown in Fig. (5).

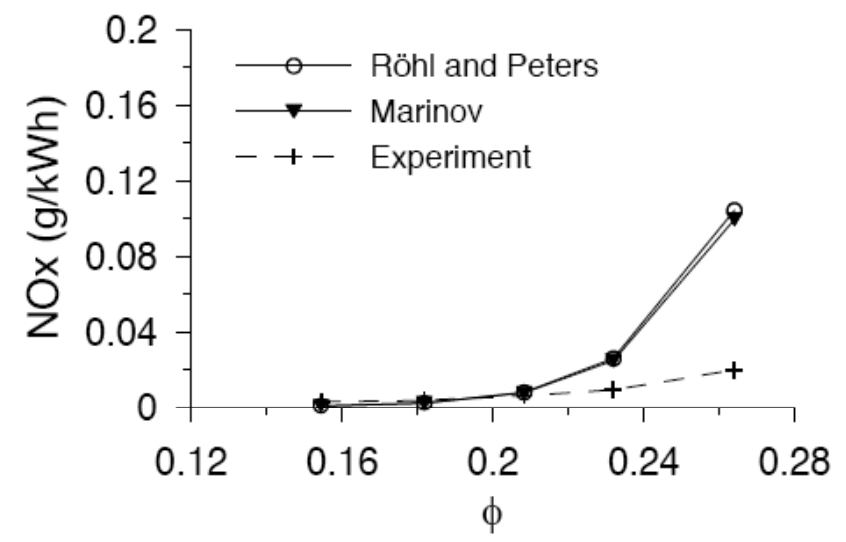

Fig. (5). Experimental and simulated results for $\mathrm{NO}_{\mathrm{x}}\left(\mathrm{NO}+\mathrm{NO}_{2}\right)$ emissions using the two oxidation mechanisms. 


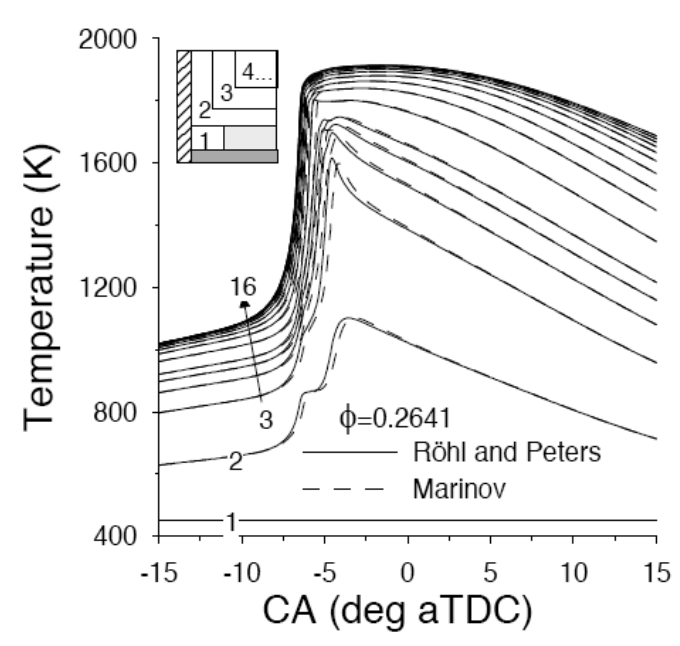

Fig. (6). Zone temperature distributions produced by the two chemical mechanisms, for the high load case $(\phi=0.2641)$.

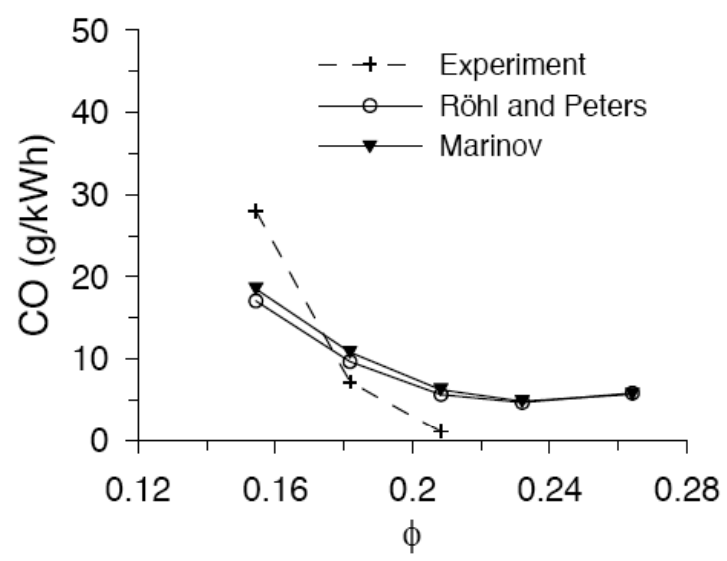

Fig. (7). Experimental and simulated results for $\mathrm{CO}$ emissions using the two oxidation mechanisms.

At the lower load cases the agreement is adequate, whilst in the higher load cases $\mathrm{NO}_{\mathrm{x}}$ emissions are over-predicted. However, it has to be emphasized that $\mathrm{NO}_{\mathrm{x}}$ emissions are very sensitive to temperature variations, especially when these variations are near the onset of $\mathrm{NO}_{\mathrm{x}}$ production, i.e. about $1800 \mathrm{~K}$. This sensitivity on temperature and the fact that simulated pressure traces are steeper than the experimental ones, is probably the main reason for the overestimation of specific $\mathrm{NO}_{\mathrm{x}}$ emissions. The aforementioned are supported by Fig. (6), in which the zone temperature distribution is shown for the two mechanisms at the highest load case. The slight underestimation of the total work produced during the closed part of the engine cycle, contributes also to the difference observed in Fig. (5).

As regards the two chemical mechanisms, Marinov's, and Röhl and Peters' mechanisms produce almost identical results, due to the similar zone temperature distributions produced by the two mechanisms (Fig. 6). The slightly higher $\mathrm{NO}_{\mathrm{x}}$ emissions predicted by the Röhl and Peters' mechanism is probably due to small differences in the predicted combustion rate. Another reason is due to the application of the same IVC conditions for both mechanisms; with the Marinov's mechanism a slightly higher initial temperature $\left(\sim 1-2{ }^{\circ} \mathrm{C}\right)$ should be used to better capture the combustion phasing.

\subsection{CO Emissions}

Simulated and experimental carbon monoxide (CO) emissions are presented in Fig. (7). The experimental emissions for the highest load cases, as presented in [18], were too low to be extracted with accuracy from the original diagrams and this is why they have not been included. The trend of decrease of $\mathrm{CO}$ with load increase is well captured. However, a discrepancy is observed concerning the absolute values.

Comparing simulated and experimental $\mathrm{NO}_{\mathrm{x}}$ and $\mathrm{CO}$ emissions (Figs. (5) and (7)), especially at high loads, we observe that although $\mathrm{NO}_{\mathrm{x}}$ emissions are over-predicted implying an overestimation of the temperature in the high temperature regions -, $\mathrm{CO}$ emissions are also higher than the experimental ones. If this $\mathrm{NO}_{\mathrm{x}}$ over-estimation was the result of a general over-estimation of the temperature in all zones, $\mathrm{CO}$ emissions should have been under-predicted, unless there was an abundance of $\mathrm{HC}$ emissions, which is the source of $\mathrm{CO}$ production. This could be the case if the effective crevice volumes were over-estimated, leading to an over-prediction of both $\mathrm{CO}$ and $\mathrm{HC}$ emissions at all loads. Although this is true for the $\mathrm{HC}$ emissions as will be shown subsequently, $\mathrm{CO}$ emissions are under-predicted at low load as shown in Fig. (7). Therefore, the most plausible explanation is the under-estimation of the work done by the engine, which can be seen in the pressure diagrams in Fig. (4) and is more pronounced at the higher loads.

The two chemical mechanisms used produce similar results for the examined cases. The maximum difference observed at low load is not significant $(\sim 9 \%)$ considering the sensitive nature of $\mathrm{CO}$ formation. This divergence is in part due to the difference in the delayed combustion phasing when using Marinov's mechanism. In Fig. (8) the in-cylinder $\mathrm{CO}$ history (as a function of degrees CA) is shown for the lowest load case, in which the difference is more pronounced. As expected, a shift is observed in the CO history and a slightly steeper net production for the Röhl and Peters' mechanism. These differences between the two mechanisms are more pronounced during combustion. However, the final $\mathrm{CO}$ values are very close.

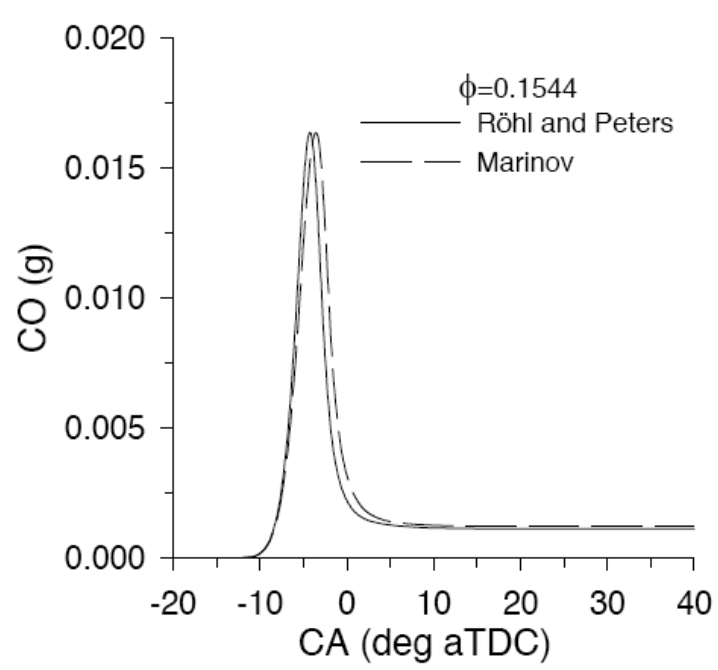

Fig. (8). In-cylinder CO history as predicted by the two chemical mechanisms, for $\phi=0.1544$. 


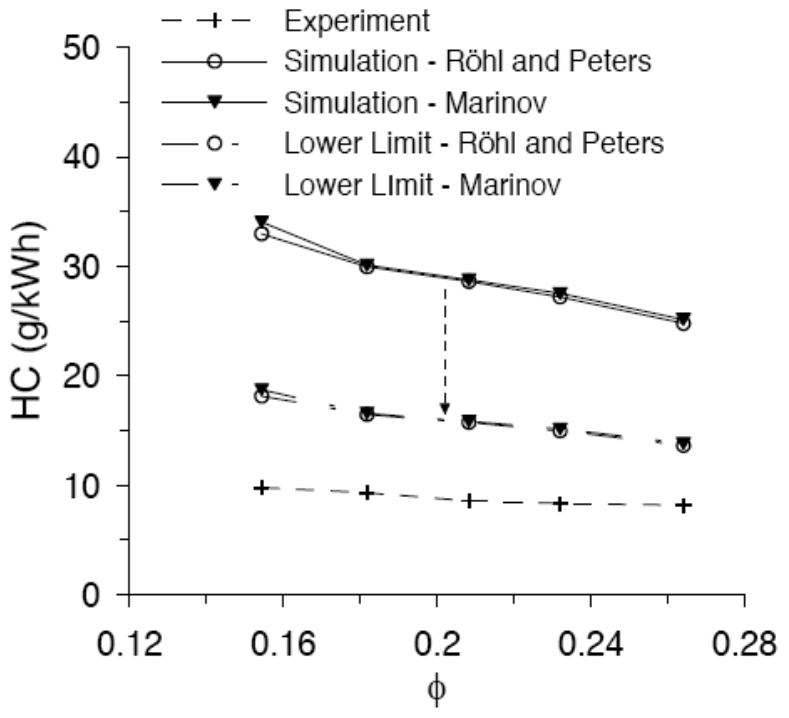

Fig. (9). Experimental and simulated results for $\mathrm{HC}$ emissions using the two oxidation mechanisms.

\subsection{HC Emissions}

Predicted and experimental (unburned) hydrocarbons (HC) emissions are shown in Fig. (9). Simulated HC emissions are indicated with solid lines. The two chemical mechanisms produce similar results as in all previous parameters tested. The greatest difference between the two mechanisms is observed in the lowest load case, but even in this case it is around $3 \%$.

The trend of $\mathrm{HC}$ reduction with increasing load is well captured by the models, but the absolute predicted values are higher than the experimental ones. One reason for this discrepancy is the under-estimation of the expansion work, which decreases the denominator of the simulated emissions (expressed as specific emission values). Another reason is that a portion of the HC located within the combustion chamber will not escape towards the exhaust valve, while the one that does escape from the combustion chamber may be partially oxidized in the exhaust manifold. Therefore, incylinder HC emissions at EVO are expected to be higher than the exhaust values as shown in the simulated results of Fig. (9).

Apart from these considerations, the results shown in Fig. (9) must be interpreted with caution. In the simulation, the $\mathrm{HC}$ emissions shown include both non oxygenated $\mathrm{HC}$ and oxygenated $\mathrm{HC}(\mathrm{OHC})$ species. It is obvious that the fraction of OHC species is high when using oxygenated fuels, as is the case with ethanol. The usual measuring device for the measurement of $\mathrm{HC}$ emissions is the Flame Ionization Detector (FID), which is essentially a carbon atom counter [4749]. The trivial procedure is to assume that the carbon atoms detected were attached to one or more hydrogen atoms, thereby interpreting the FID ppm indication as $\mathrm{CH}$ or $\mathrm{CH}_{4}$ concentration. According to this procedure, to transform the "ppm" indication into grams it is necessary to multiply it by the total number of exhaust gas moles expelled during the cycle and by an appropriate molar mass. However, this procedure does not necessarily provide the actual mass of the total unburned hydrocarbons due to two main reasons: firstly, not all carbon atoms passed through the FID are detected; carbon atoms attached to oxygen atoms are not easily detected especially when the oxygen and carbon form a carbonyl group $(\mathrm{C}=\mathrm{O})$. Secondly, even if these oxygenated carbon atoms were detected by the FID, they would be assigned a molar mass of $13 \mathrm{~kg} / \mathrm{kmol}$ (if considered as $\mathrm{CH}$ ) or at most $16 \mathrm{~kg} / \mathrm{kmol}$ (if considered as $\mathrm{CH}_{4}$ ), whereas the actual molar mass of the oxygenated carbon group would be at least $12+16=28 \mathrm{~kg} / \mathrm{kmol}$. The error involved in such an assessment, depends on the actual composition of the unburned HC. It becomes significant when the FID span (calibration) gas is an ordinary non-oxygenated hydrocarbon and the engine exhaust gases (the sample gas) consist of oxygenated compounds.

In order to investigate the aforementioned line of thought, the composition of the predicted HC species is given in Fig. (10) for (a) the highest and (b) the lowest load cases. In this figure, all $\mathrm{HC}$ species found in quantities greater than $1.0 \times 10^{-10}$ are shown.

Several conclusions can be drawn from the figure: firstly, from the 19 additional species that the Marinov mechanism includes and the Röhl and Peters excludes, only methanol $\left(\mathrm{CH}_{3} \mathrm{OH}\right)$ and formic acid $(\mathrm{HCOOH})$ are present in the Marinov predicted results. This indicates that for the cases under study, the omission of the remaining 17 species in the Röhl and Peters mechanism does not affect significantly the composition of the total HC produced.

Secondly, there are some differences in the quantities of the remaining common species. For example, at the high load case (Fig. 10b) the Röhl and Peters' mechanism predicts more acetaldehyde $\left(\mathrm{CH}_{3} \mathrm{CHO}\right)$ than methane $\left(\mathrm{CH}_{4}\right)$, while with Marinov's mechanism this trend is reversed, indicating a qualitative difference between the two mechanisms.

With the results presented in Fig. (10) it is possible to assess theoretically the performance of a hypothetical FID analyzer, in which the simulated $\mathrm{HC}$ emissions at EVO could be introduced. Two issues are of concern in the following analysis. Firstly, how much of the carbon atoms of the HC predicted in Fig. (10) would have been detected by such a hypothetical FID measurement. The second issue regards the transformation of the FID indication on a mass basis. Specifically, the concern is what portion of the known simulated HC mass would have been calculated from the FID indication, if all carbon atoms detected were assigned a molar mass of $16 \mathrm{~kg} / \mathrm{kmol}$ (the molar mass of $\mathrm{CH}_{4}$ ).

In order to proceed, the relative FID response of each species must be known. The relative FID response $(R R)$ of a species is the number of carbon atoms detected by the FID analyzer per molecule of the species. For most of the nonoxygenated hydrocarbons (alkanes, alkenes, alkynes etc), the relative FID response equals the number of carbon atoms in the species molecule. Table 5 includes the relative FID responses of the species shown in Fig. (10). These values were taken from Refs [50] and [51], and are used herein as indicated in Ref. [52].

Using the relative FID responses of each species and the kmol of each species, an estimation of the error of the FID analyzer in detecting the carbon atoms can be given via Eq. (16). 

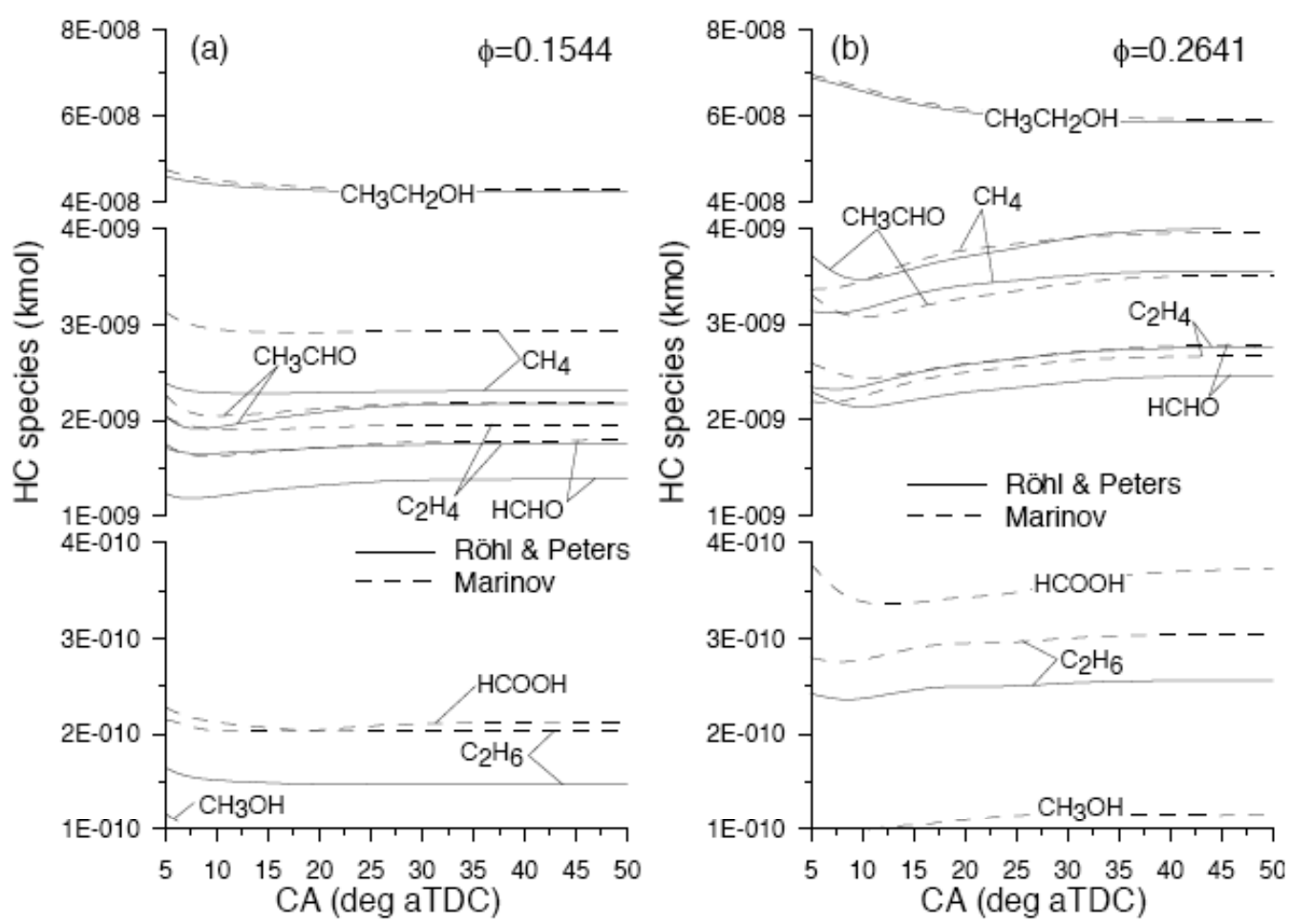

Fig. (10). In-cylinder HC species predicted by the Röhl and Peters' (solid lines) and Marinov's (dashed lines) mechanisms for the highest (a), and the lowest (b) load cases.

Table 5. FID Relative Response for Selected Hydrocarbons

\begin{tabular}{|c|c|c|}
\hline Species & $\begin{array}{c}\text { Carbon Atoms in } \\
\text { Molecule }\end{array}$ & $\begin{array}{c}\text { FID Relative } \\
\text { Response (RR) }\end{array}$ \\
\hline \hline $\mathrm{C}_{2} \mathrm{H}_{5} \mathrm{OH}$ & 2 & $1.59^{\mathrm{a}}$ \\
\hline $\mathrm{HCHO}$ & 1 & $0^{\mathrm{a}}$ \\
\hline $\mathrm{CH}_{3} \mathrm{CHO}$ & 2 & $1($ est.) \\
\hline $\mathrm{CH}_{4}$ & 1 & $1^{\mathrm{b}}$ \\
\hline $\mathrm{C}_{2} \mathrm{H}_{4}$ & 2 & $1.99^{\mathrm{a}}$ \\
\hline $\mathrm{C}_{2} \mathrm{H}_{6}$ & 2 & $1.97^{\mathrm{a}}$ \\
\hline $\mathrm{HCOOH}^{\mathrm{O} O \mathrm{O}}$ & 1 & $0^{\mathrm{a}}$ \\
\hline $\mathrm{CH}_{3} \mathrm{OH}$ & 1 & $0.52^{\mathrm{a}}$ \\
\hline
\end{tabular}

${ }^{\mathrm{a}}$ from Ref. [50], ${ }^{\mathrm{b}}$ from Ref. [51], (est.) estimation

$\operatorname{Rerr}_{F I D}=\frac{\sum_{m} c_{m} n_{m}-\sum_{m} R R_{m} n_{m}}{\sum_{m} R R_{m} n_{m}}$

Where Rerr $_{F I D}$ is the relative error with respect to the FID measurement, $c_{m}$ the carbon atoms per molecule of species $m, n_{m}$ the kmoles of species $m$ in the exhaust gases, and $R R_{m}$ the relative FID response for species $m$. According to these definitions, the product $c_{m} \cdot n_{m}$ is the moles of carbon atoms originating from species $m$. The product $R R_{m} \cdot n_{m}$ yields the moles of carbon atoms detected by the FID. Since the carbon atoms are directly proportional to the moles of carbon -the proportionality constant being the Avogadro Number $\mathrm{N}_{\mathrm{A}^{-}}$, Eq. (16) also provides the relative error in carbon atoms detection. More details on the aforementioned method can be found in [52]. The relative error found via Eq. (16) for the high and low load cases depicted in Fig. (10) is approximately $28 \%$ for both mechanisms. This means that if the predicted HC emissions were introduced in the FID analyzer, the carbon atom FID indication should be enhanced by $28 \%$ to provide the predicted carbon atoms.

Moreover, if each carbon atom detected by the FID was assumed to originate from $\mathrm{CH}_{4}$ and assigned the molar mass of $16 \mathrm{~kg} / \mathrm{kmol}$, then the HC mass determined from the hypothetical FID measurement would be $\sum_{m} R R_{m} \cdot n_{m} \cdot 16 \mathrm{~kg}$.

The ratio of this total HC mass assigned from the FID measurement is approximately $55 \%$ of the total simulated HC mass for both mechanisms, for the two extreme load cases. This means that if the simulated HC emissions were introduced in an FID analyzer and its indication transformed to $\mathrm{HC}$ mass by the procedure outlined, this HC mass assigned would be about half the HC mass introduced into the FID. According to the aforementioned, the indication of an FID analyzer, through which the simulated HC pass, would yield $55 \%$ of the simulated HC mass. This reduced HC mass corresponds to the lower limit of Fig. (9). This lower limit is still higher than the experimental $\mathrm{HC}$ values, probably because of reasons explained in the beginning of this subsection.

It is evident that most of the aforementioned issues concern not only HCCI engine combustion but also other types, such as SI engine combustion. However, they are plausible 
assumptions that cannot be derived in a theoretical analysis. Certainly, experimental investigation is needed to establish their validity.

\section{CONCLUSIONS}

The analysis results show adequate agreement with the experimental ones. The heat release rates are somewhat overestimated and a generally more steep pressure rise is observed relative to the experimental cases. At low loads the duration of combustion is underestimated, probably due to poor combustion efficiency that induces inhomogeneties within the combustion chamber.

There is a slight difference in the combustion phasing of the two mechanisms for the same initial conditions. This is the result of the slightly higher combustion rate predicted by the Röhl and Peters' mechanism relative to Marinov's mechanism, despite the fact that the predicted initial heat release is the same for the two mechanisms. However, this does not induce significant differences in the predicted performance.

The predictions of $\mathrm{NO}_{\mathrm{x}}, \mathrm{CO}$ and $\mathrm{HC}$ emissions are essentially the same for the two mechanisms, with the greatest disagreement occurring between predicted $\mathrm{CO}$ emissions $(\sim 9 \%)$ at the low load cases. This is probably connected with the slightly lower combustion rate predicted by Marinov, as already mentioned.

As regards the comparison with the experimental results, $\mathrm{NO}_{\mathrm{x}}$ emissions trends are captured by the model while being overestimated at high loads. This results from the overestimation of the zone temperature in a portion of the hotter zones for the higher load cases. The slight underestimation of the work produced is also a contributing factor to this discrepancy.

$\mathrm{CO}$ and $\mathrm{HC}$ emissions trends are also captured by the model for both the oxidation mechanisms. The absolute $\mathrm{CO}$ values are comparable to the measured ones, but the discrepancy is larger for the $\mathrm{HC}$ emissions. Reasons for this discrepancy could be attributed to the under-estimation of the expansion work, and the fact that the comparison is made between exhaust measured and in-cylinder quantities at EVO. The latter are expected to be higher than the former ones, due to partial expulsion of $\mathrm{HC}$ and subsequent oxidation during the exhaust phase.

Another reason for this discrepancy could be the nature of the unburned $\mathrm{HC}$ and the corresponding ability of a conventional FID analyzer to detect oxygenated compounds. Taking into account the simulated HC species concentration and their relative FID response, it was estimated that if the simulated $\mathrm{HC}$ emissions of the highest and lowest load cases were introduced in an FID analyzer, 28\% of the carbon atoms would have escaped without detection. Moreover, the mass assigned based on the FID measurement would have underestimated the total $\mathrm{HC}$ mass by $45 \%$, regardless of the oxidation mechanism used in the simulation.

The analysis of the simulated HC emissions confirmed the dominance of oxygenated species in the $\mathrm{HC}$ and showed that the two mechanisms predict essentially the same dominant HC species, with the exception of formic acid $(\mathrm{HCOOH})$ and to a lesser extent methanol $\left(\mathrm{CH}_{3} \mathrm{OH}\right)$. The latter two are excluded in the Röhl and Peters' mechanism. However, the total $\mathrm{HC}$ mass predicted by the two mechanisms lie very close.

In conclusion, the reduced oxidation mechanism utilized herein produces essentially identical results with the detailed mechanism, as regards $\mathrm{HCCI}$ engine performance and emissions. The main gain from the reduced mechanism is the decrease of computational time, since Röhl and Peters' mechanism requires only $50 \%$ of the computational time for the cases examined in the present study, while still using $70 \%$ of the species and $60 \%$ of the reactions considered in the detailed mechanism of Marinov.

\section{ACKNOWLEDGEMENTS}

We would like to thank Professor Bengt Johansson and $\mathrm{Ph}$.D. student Vittorio Manente from the Lund Institute of Technology, Sweden, for providing freely the experimental data used in this paper, for their willingness and for their useful comments.

\section{NOMENCLATURE}

\begin{tabular}{|c|c|c|}
\hline$B$ & $=$ & Cylinder bore (m) \\
\hline$c$ & $=$ & Carbon atoms in a molecule \\
\hline$h$ & $=$ & Molar specific enthalpy $(\mathrm{J} / \mathrm{kmol})$ \\
\hline$i$ & $=$ & Any zone \\
\hline$j$ & $=$ & Any chemical species \\
\hline$J$ & $=$ & Number of chemical species \\
\hline$k$ & $=$ & Thermal conductivity (W/m K) \\
\hline K & $=$ & $\begin{array}{l}\text { Number of carbon atoms originating } \\
\text { from oxygenated species }\end{array}$ \\
\hline$L$ & $=$ & $\begin{array}{l}\text { Number of carbon atoms originating } \\
\text { from non-oxygenated species }\end{array}$ \\
\hline$m$ & $=$ & Mass (kg) \\
\hline$M$ & $=$ & Molar mass $(\mathrm{kg} / \mathrm{kmol})$ \\
\hline $\bar{M}$ & $=$ & Average zone molar mass $(\mathrm{kg} / \mathrm{kmol})$ \\
\hline$n_{j}$ & $=$ & kmoles of species $\mathrm{j}(\mathrm{kmol})$ \\
\hline$N_{A}$ & $=$ & Avogadro number $6.023 \times 10^{23} \mathrm{~mol}^{-1}$ \\
\hline$P$ & $=$ & Pressure $\left(\mathrm{N} / \mathrm{m}^{2}\right)$ \\
\hline$\dot{q}$ & $=$ & Heat flux $\left(\mathrm{W} / \mathrm{m}^{2}\right)$ \\
\hline$Q_{i}$ & $=$ & Net heat gained by zone i $(\mathrm{J})$ \\
\hline$R_{u}$ & $=$ & Universal gas constant $8314 \mathrm{~J} / \mathrm{kmol} \mathrm{K}$ \\
\hline$R R$ & $=$ & Relative FID response to a compound \\
\hline$r$ & $=$ & Distance (m) \\
\hline$S$ & $=$ & Cylinder height (m) \\
\hline$T$ & $=$ & Temperature (K) \\
\hline $\bar{T}$ & $=$ & Mean gas temperature $(\mathrm{K})$ \\
\hline$t$ & $=$ & Thickness (m), or time (s) \\
\hline$u$ & $=$ & Velocity (m/s) \\
\hline$U$ & $=$ & Internal energy $(\mathrm{J})$ \\
\hline
\end{tabular}




$\begin{array}{lll}V & = & \text { Volume }\left(\mathrm{m}^{3}\right) \\ z & = & \text { Number of zones }\end{array}$

Greek symbols

$$
\begin{aligned}
& \alpha \\
& \kappa \\
& \phi \\
& \mu \\
& \rho
\end{aligned}
$$

\section{Subscripts}

$\begin{array}{lll}\text { act } & = & \text { Actual } \\ \text { cyl } & = & \text { Cylinder } \\ \mathrm{d} & = & \text { Detected } \\ \text { exh } & = & \text { Exhaust } \\ \text { in } & = & \text { Inlet } \\ 1 & = & \text { Laminar } \\ \mathrm{m} & = & \text { Any hydrocarbon species } \\ \text { meas } & = & \text { Measured } \\ \text { min } & = & \text { Minimum } \\ \mathrm{n} & = & \text { Normal } \\ \text { net } & = & \text { Net value (including all four strokes) } \\ \mathrm{st} & = & \text { Stoichiometric } \\ \mathrm{t} & = & \text { Turbulent } \\ \text { tot } & = & \text { Total } \\ \mathrm{w} & = & \text { Wall }\end{array}$

Superscripts

$\begin{array}{lll}* & = & \text { Characteristic value } \\ + & = & \text { Dimensionless value }\end{array}$

Dimensionless numbers

$\operatorname{Pr}$ $=\quad$ Prandtl number

\section{Abbreviations}

$\begin{array}{lll}\mathrm{a} & = & \text { After } \\ \mathrm{b} & = & \text { Before } \\ \mathrm{BDC} & = & \text { Bottom dead center } \\ \mathrm{CA} & = & \text { Crank angle } \\ \mathrm{CO} & = & \text { Carbon monoxide } \\ \mathrm{CFD} & = & \text { Computational fluid dynamics } \\ \mathrm{CI} & = & \text { Compression ignition } \\ \mathrm{CR} & = & \text { Compression ratio }\end{array}$

\begin{tabular}{|c|c|c|}
\hline EGR & $=$ & Exhaust gas recirculation \\
\hline EVC & $=$ & Exhaust valve closing \\
\hline EVO & $=$ & Exhaust valve opening \\
\hline FID & $=$ & Flame ionization detector \\
\hline $\mathrm{HC}$ & $=$ & (Unburned) hydrocarbons \\
\hline $\mathrm{HCCI}$ & $=$ & $\begin{array}{l}\text { Homogeneous charge compression ig- } \\
\text { nition }\end{array}$ \\
\hline HRR & $=$ & Heat release rate $(\mathrm{J} / \mathrm{deg})$ \\
\hline imep & $=$ & Indicated mean effective pressure (bar) \\
\hline IVC & $=$ & Inlet valve closing \\
\hline IVO & $=$ & Inlet valve opening \\
\hline $\mathrm{NO}_{\mathrm{x}}$ & $=$ & Nitrogen oxides \\
\hline $\mathrm{OHC}$ & $=$ & Oxygenated (unburned) hydrocarbons \\
\hline ppm & $=$ & Parts per million \\
\hline PRF & $=$ & Primary reference fuel \\
\hline SI & $=$ & Spark ignition \\
\hline DC & $=$ & Top dead center \\
\hline
\end{tabular}

\section{REFERENCES}

[1] Rakopoulos, C.D.; Antonopoulos, K.A.; Rakopoulos, D.C.; Hountalas, D.T. Multi-zone modeling of combustion and emissions formation in DI diesel engine operating on ethanol-diesel fuel blends. Energy Convers. Manage., 2008, 49, 625-43.

[2] Rakopoulos, C.D.; Antonopoulos, K.A.; Rakopoulos, D.C. Development and application of multi-zone model for combustion and pollutants formation in direct injection diesel engine running with vegetable oil or its bio-diesel. Energy Convers. Manage., 2007, 48, 1881-901.

[3] Rakopoulos, D.C.; Rakopoulos, C.D.; Kakaras E.C.; Giakoumis E.G. Effects of ethanol-diesel fuel blends on the performance and exhaust emissions of heavy duty DI diesel engine. Energy Convers. Manage., 2008, 49, 3155-62.

[4] Rakopoulos, C.D.; Rakopoulos, D.C.; Hountalas, D.T.; Giakoumis, E.G.; Andritsakis, E.C. Performance and emissions of bus engine using blends of diesel fuel with bio-diesel of sunflower or cottonseed oils derived from Greek feedstock. Fuel, 2008, 87, 14757.

[5] Rakopoulos, D.C.; Rakopoulos, C.D.; Giakoumis, E.G.; Papagiannakis, R.G.; Kyritsis, D.C. Experimental-stochastic investigation of the combustion cyclic variability in HSDI diesel engine using ethanol-diesel fuel blends. Fuel, 2008, 87, 1478-91.

[6] Anderson, E.; Kyritsis, D.; Coverdill, R.; Lee, C-F. Experimental Evaluation of Electrostatically Assisted Injection and Combustion of Ethanol-Gasoline Mixtures for Automotive Applications. SAE Paper no. 2010-01-0171; 2007.

[7] Yan, J.; Lin, T. Biofuels in Asia. Appl. Energy, 2009, 86, S1-S10.

[8] Chapman E.M.; Boehman A.L. Pilot ignited premixed combustion of dimethyl ether in a turbodiesel engine. Fuel Process. Technol., 2008, 89, 1262-71.

[9] Szybist, J.P.; Song, J.; Alam, M.; Boehman, A.L. Biodiesel combustion, emissions and emission control. Fuel Process. Technol., 2007, 88, 679-91.

[10] Koc, M.; Sekmen, Y.; Topgul, T.; Yucesu, H.S. The effects of ethanol-unleaded gasoline blends on engine performance and exhaust emissions in a spark-ignition engine. Renewable Energy, 2009, 34, 2101-6.

[11] Pang, X.; Mua, Y.; Yuan, J.; Hea, H. Carbonyls emission from ethanol-blended gasoline biodiesel-ethanol-diesel used in engines. Atmos. Environ., 2008, 42, 1349-58.

[12] Rakopoulos, C.D.; Michos, C.N. Development and validation of a multi-zone combustion model for performance and nitric oxide formation in syngas fueled spark ignition engine. Energy Convers. Manage., 2008, 49, 2924-38. 
[13] Yao, M.; Zheng, Z.; Liu, H. Progress and recent trends in homogeneous charge compression ignition (HCCI) engines. Prog. Energy Combust. Sci., 2009, 35, 398-437.

[14] Shibata, G.; Oyama, K.; Urushihara, T.; Nakano, T. The effect of fuel properties on low and high temperature heat release and resulting performance of an HCCI engine. SAE Paper no. 2004-01$0553 ; 2004$.

[15] Maurya, R. K; Agarwal, AK. Experimental investigation of the effect of the intake air temperature and mixture quality on the combustion of methanol- and gasoline-fuelled homogeneous charge compression ignition engines. Proc. Inst. Mech. Eng., Part D, J. Automob. Eng., 2010, doi: 10.1243/09544070JAUTO1238.

[16] Yao, M.; Chen, Z.; Zheng, Z.; Zhang, B.; Xing, Y. Study on the controlling strategies of homogeneous charge compression ignition combustion with fuel of dimethyl ether and methanol. Fuel, 2006, 85, 2046-56.

[17] Yap, D.; Peucheret, S.M.; Megaritis, A.; Wyszynski, M.L.; Xu, H. Natural gas HCCI engine operation with exhaust gas fuel reforming. Int. J. Hydrogen Energy, 2006, 31, 587-95.

[18] Christensen, M.; Einewall, P.; Johansson, B. Homogeneous charge compression ignition (hcci) using isooctane, ethanol and natural gas - A comparison with spark-ignition operation. SAE Paper no. 972874; 1997.

[19] Christensen, M.; Johansson, B.; Amneus, P.J.H.; Mauss, F. Supercharged homogeneous charge compression ignition. SAE Paper no. 980787; 1998.

[20] Lü, X.; Ji, L.; Zu, L.; Hou, Y.; Huang, C.; Huang Z. Experimental study and chemical analysis of n-heptane homogeneous charge compression ignition combustion with port injection of reaction inhibitors. Combust. Flame, 2007, 149, 261-70.

[21] Lü, X.; Hou, Y.; Zu, L.; Huang, Z. Experimental study on the autoignition and combustion characteristics in the homogeneous charge compression ignition (HCCI) combustion operation with ethanol/nheptane blend fuels by port injection. Fuel, 2006, 85, 2622-31.

[22] Mack, H.J.; Aceves, S.M.; Dibble, R.W. Demonstrating direct use of wet ethanol in a homogeneous charge compression ignition (HCCI) engine. Energy, 2009, 34, 782-7.

[23] Kong, S-C. A study of natural gas/DME combustion in HCCI engines using CFD with detailed chemical kinetics. Fuel, 2007, 86, 1483-9.

[24] Mack, J.H.; Flowers, D.L.; Buchholzc, B.A.; Dibble, R.W. Investigation of HCCI combustion of diethyl ether and ethanol mixtures using carbon 14 tracing and numerical simulations. Proc. Combust. Inst., 2005, 30, 2693-700.

[25] Hoffman, S.R.; Abraham, J. A comparative study of $n$-heptane, methyl decanoate, and dimethyl ether combustion characteristics under homogeneous-charge compression-ignition engine conditions. Fuel, 2009, 88, 1099-108.

[26] Jia, M.; Xie, M. A chemical kinetics model of iso-octane oxidation for HCCI engines. Fuel, 2006, 85, 2593-604.

[27] Machrafi, H.; Cavadias, S. An experimental and numerical analysis of the influence of the inlet temperature, equivalence ratio and compression ratio on the HCCI auto-ignition process of Primary Reference Fuels in an engine. Fuel Process. Technol., 2008, 89, 1218-26.

[28] Machrafi, H.; Cavadias, S.; Gilbert, P. An experimental and numerical analysis of the HCCI auto-ignition process of primary reference fuels, toluene reference fuels and diesel fuel in an engine, varying the engine parameters. Fuel Process. Technol., 2008, 89, 1007-16.

[29] Kirchen, P.; Shahbakhti, M.; Koch, C.R. A skeletal kinetic mechanism for PRF combustion in HCCI engines. Combust. Sci. Technol., 2007, 179, 1059-83.
[30] Komninos. N.P. Assessing the effect of mass transfer on the formation of $\mathrm{HC}$ and $\mathrm{CO}$ emissions in $\mathrm{HCCI}$ engines, using a multi-zone model. Energy Convers. Manage., 2009, 50, 1192-201.

[31] Komninos, N.P. Modeling HCCI combustion: Modification of a multi-zone model and comparison to experimental results at varying boost pressure. Appl. Energy, 2009, 86, 2141-51.

[32] Komninos, N.P.; Hountalas, D.T.; Rakopoulos, D.C. A parametric investigation of hydrogen HCCI combustion using a multi-zone model approach. Energy Convers. Manage., 2007, 48, 2934-41.

[33] Incropera, F.P.; DeWitt, D.P. Introduction to Heat Transfer, 3rd ed.; John Wiley: New York, 1996.

[34] Yang, J.; Martin, J.K. Approximate solution - one-dimensional energy equation for transient, compressible, low Mach number turbulent boundary layer flows. Trans. ASME, J. Heat Transfer, 1989, 111, 619-24.

[35] Kong, S.; Ayoubm N.; Reitz, R.D. Modeling combustion in compression ignition homogeneous charge engines. SAE Paper no. 920512; 1992.

[36] Reitz, R.D. Assessment of wall heat transfer models for premixedcharge engine combustion computations. SAE Paper no. 910267 1991.

[37] Jia, M.; Zhao, Xie, M.; Peng, Z. A comparative study of multi-zone combustion models for HCCI engines. SAE Paper no. 2008-010064; 2008.

[38] Kongsereeparp, P.; Checkel, M.D. Investigating the effects of reformed fuel blending in a methane- or n-heptane-HCCI engine using a multi-zone model. SAE Paper no. 2007-01-0205; 2007.

[39] Kongsereeparp, P; Checkel, M.D. Novel method of setting initial conditions for multi-zone HCCI combustion modeling. SAE Paper no. 2007-01-0674; 2007.

[40] Liu, H.; Xie, M.; Wu, D. Simulation of a porous medium (PM) engine using a two-zone combustion model. Appl. Therm. Eng., 2009, 29, 3189-97.

[41] Marinov, N.M. A detailed chemical kinetic model for high temperature ethanol oxidation. Int. J. Chem. Kinet., 1999, 31, 183220.

[42] https://www-pls.llnl.gov/?url=science_and_technology-chemistrycombustion-ethanol (2009).

[43] Röhl, O.; Peters, N. A reduced mechanism for ethanol oxidation. European Combustion Meeting, Vienna, Austria, 14-17 April, 2009.

[44] http://www.itv.rwth-aachen.de/index.php?id=16\&L=5 (2009).

[45] http://www.tfd.chalmers.se/ valeri/MECH.html

[46] Westbrook C.K.; Pitz W.J.; Herbineta O.; Curran H.J.; Silke E.J. A comprehensive detailed chemical kinetic reaction mechanism for combustion of $\mathrm{n}$-alkane hydrocarbons from n-octane to nhexadecane. Combust. Flame, 2009, 156, 181-99.

[47] Heywood, J.B. Internal Combustion Engine Fundamentals. McGraw Hill: New York, 1988.

[48] Christian, G.D. Analytical Chemistry. 6th ed. John Wiley: New York, 2004.

[49] Grob, R.L. Modern Practice of Gas Chromatography. John Wiley: New York, 1977.

[50] Schofield, K. The enigmatic mechanism of the flame ionization detector: Its overlooked implications for fossil fuel combustion modeling. Prog Energy Combust. Sci., 2008, 34, 330-50.

[51] Cheng, W.K.; Summers, T.; Collings, N. The fast-response flame ionization detector. Prog. Energy Combust. Sci., 1998, 24, 89-124.

[52] Komninos, N.P.; Rakopoulos, C.D. Numerical investigation into the formation of $\mathrm{CO}$ and oxygenated and nonoxygenated hydrocarbon emissions from isooctane- and ethanol-fueled $\mathrm{HCCI}$ engines. Energy Fuels, 2010, 24 (3), 165-567.

This is an open access article licensed under the terms of the Creative Commons Attribution Non-Commercial License (http://creativecommons.org/licenses/by-nc/3.0/) which permits unrestricted, non-commercial use, distribution and reproduction in any medium, provided the work is properly cited. 